\title{
Predictors of medication nonadherence in patients with systemic lupus erythematosus in Sichuan: a cross-sectional study
}

This article was published in the following Dove Press journal: Patient Preference and Adherence

Xia Xie

Hui Yang

Anliu Nie

Hong Chen*

Jiping Li*

West China School of Nursing and Department of Nursing, West China Hospital, Sichuan University,

Chengdu, China

*These authors contributed equally to this work
Correspondence: Hong Chen

West China School of Nursing and Department of Nursing, West China Hospital, Sichuan University, No 37 Guoxue Xiang, Chengdu 61004I, China Tel +8602885422684

Email 1366109878@qq.com
Purpose: The aim of this study was to determine the prevalence and predictors of medication nonadherence among patients with systemic lupus erythematosus (SLE) in Sichuan.

Patients and methods: A cross-sectional investigation was performed. Participants were recruited by consecutive sampling from the Rheumatic Clinic of a university hospital between June and September 2016. Patients' self-reported medication adherence was assessed by the eight-item Morisky Medication Adherence Scale. Additional surveys included patients' demographics, and clinical and treatment characteristics. Logistic regression analysis was used to identify the predictors of medication nonadherence.

Results: A total of 140 patients were included in analysis. The percentage of patients classified as nonadherent to medication was $75 \%$. Low education, rural residency, childlessness, limited comprehension of medication instructions, side effects experienced, dissatisfaction with treatment and better physical health were associated with an increased risk of nonadherence.

Conclusion: This study demonstrated a high prevalence of medication nonadherence among SLE patients in Sichuan, and factors associated with the nonadherence are multifaceted. Interventions for these factors, such as appropriate adjustment of the service resources for patients with rheumatic disease in rural communities and improved communication between the health care providers and the patients, may contribute to improve the medication adherence of this cohort.

Keywords: systemic lupus erythematosus, medication management, adherence, predictors

\section{Plain language summary}

Systemic lupus erythematosus (SLE) is a common connective tissue disease with multiorgan involvement. It is associated with significant morbidity and mortality and has considerable adverse effects on the perception of health and daily activity of the patients. It is important to understand the prevalence and factors associated with medication nonadherence in these patients, as this is likely to contribute to develop targeted interventions to improve patients' adherence and their outcomes. However, prevalence and predictors of adherence problems in SLE patients, especially in those in developing countries such as China, have been inadequately studied. Therefore, Ms Xia's team preformed this study to investigate the prevalence and predictors of medication nonadherence in Chinese patients with SLE. This study included 140 patients from a university hospital between June and September 2016. The results show that there is a great prevalence of medication nonadherence among SLE patients in Sichuan, China. Low education, rural residency, childlessness, limited comprehension of medication instructions, side effects experienced, dissatisfaction with treatment and better physical health were associated with an increased risk of nonadherence. These findings suggest that adherence of patients with SLE may be improved by interventions for these predictors, such as appropriate adjustment of the service 
resources for patients with rheumatic disease in rural communities and improved communication between the health care providers and the patients, including the need for health care providers to identify and discuss any questions and concerns which the patient may have regarding their disease and its medications.

\section{Introduction}

Systemic lupus erythematosus (SLE) is a common connective tissue disease with multiorgan involvement. It occurs worldwide and disproportionally affects the people of African, Hispanic and Asia-Pacific origin. ${ }^{1,2}$ In numerous studies, SLE has been shown to be associated with significant morbidity and mortality and has considerable adverse effects on the perception of health and daily activity of the patients. ${ }^{3-5}$ Early diagnosis and treatment and, most importantly, patients' adherence to therapy recommendations are crucial for the improvement of patients' outcomes. ${ }^{6,7}$ Conversely, inadequate adherence to drug therapy in SLE has been associated with a higher risk of flares, morbidity, hospitalizations and poor renal outcome. ${ }^{8-10}$ Thus, it is important to understand the prevalence and factors associated with medication nonadherence in these patients, as this is likely to contribute to develop targeted interventions to improve patients' adherence and their outcomes.

Although several studies have explored the extent and risk factors of poor medication adherence among SLE patients, predictors of nonadherence among SLE patients are not well studied. ${ }^{11,12}$ A systematic review demonstrated that the prevalence of medication nonadherence in SLE patients ranged from $3 \%$ to $76 \%$, depending on the different assessment methods and the study population. ${ }^{11}$ Patients being nonadherent to medication recommendations may be attributed to a number of causes, including age, ${ }^{13}$ occurrence of adverse drug reactions, ${ }^{14,15}$ having to take medicines more than once daily ${ }^{16}$ and being a rural resident. ${ }^{12,17}$ Moreover, marital status, ${ }^{13,16}$ education level, ${ }^{16,17}$ duration of the disease ${ }^{13}$ and number of comorbidities ${ }^{16}$ may predict treatment adherence in SLE patients, but some studies showed these factors were not risk factors for medication nonadherence of SLE patients. ${ }^{18,19}$ Additionally, comprehension of medication instructions, treatment satisfaction and perceived physical health are often associated with nonadherence reported by other chronic disease groups. ${ }^{20-23}$ However, the relationship between these factors and nonadherence in patients with SLE is unknown. Also, previous adherence studies on SLE were mainly carried out in developed countries. ${ }^{11,12}$ To our knowledge, there is scant information about medication nonadherence of patients with SLE in developing countries such as China.
In view of this, the aims of the present study were: 1) to determine the prevalence of medication nonadherence of SLE patients in Sichuan, China and 2) to further explore its predictors.

\section{Patients and methods Study design and population}

This study was a cross-sectional study. The primary investigators of this study (XX and HY) recruited participants in person by consecutive sampling from the Rheumatic Clinic of West China Hospital, Sichuan University between June and September 2016. To be included in the study, participants had to be $\geq 18$ years; had to be diagnosed with SLE using the criteria of American College of Rheumatology of 1997; ${ }^{24}$ should have been undergoing treatment with glucocorticoids, hydroxychloroquine and/or immunosuppressants at the time of enrollment, and should have adequate cognitive status as determined by communicating with the patients. Patients who could not speak/read in the Chinese language were excluded. Also, patients who were illiterate were excluded from the study.

\section{Measures}

All participants completed three paper questionnaires: sociodemographic, clinical and treatment characteristics survey; the Chinese version of the eight-item Morisky Medication Adherence Scale (MMAS-8) and the Chinese version of the Medical Outcomes Study 36-item Short Form (SF-36). Additionally, the investigators completed the Systemic Lupus Erythematosus Disease Activity Index 2000 (SLEDAI-2K) based on the information provided by hospital records and the patients.

\section{Sociodemographic, clinical and treatment characteristics survey}

In this study, the sociodemographic, clinical and treatment characteristics survey included age, gender, residence, education level, marital status, fertility status, employment status, medical insurance, diagnosis duration of SLE, chronic comorbidity and type of SLE medicine. The questionnaire also addressed the following: satisfaction with treatment, frequency of dosing more than once daily, comprehension of medical instructions and presence of side effects. These indicators were measured by the following questions: Are you satisfied with the current treatment? Is your frequency of medication dosing more than once daily? Do you fully understand the medication instructions provided by your primary physician or nurse? Do you have any side effects such as concentric obesity, full moon face, nausea, vomiting and 
so on"? For each question, the response options included "yes" and "no".

\section{The Chinese version of the MMAS- 8}

The MMAS- 8 Chinese scale was used to investigate medication adherence. The scale is a self-administered instrument with eight items, of which items 1-7 have two response options (yes/no) and item 8 is rated on a 5-point Likert scale. The total score ranges from 0 to $8 .^{25,42}$ A cutoff score of 6 is recommended to classify respondents as nonadherence (MMAS-8 $\leq 6)$ or adherence (MMAS- $8>6$ ). ${ }^{26}$ Previous studies have confirmed that the scale is simple and practical and has good reliability and validity. ${ }^{27,43}$ The Cronbach's $\alpha$ coefficient of the scale in this study was 0.81 .

\section{The Chinese version of the Medical Outcomes Study SF-36}

The SF-36 contains eight domains, which can be further summarized into two component scores: physical component summary (PCS) and mental component summary (MCS). After recoding, both the components can reach a maximum of 100. The SF-36 has been tested and recommended to be used in Chinese patients with SLE. ${ }^{28}$ In this study, participants' physical and mental health was measured by the SF-36 PCS and the SF-36 MCS, respectively. Higher scores indicate better physical and mental health. The Cronbach's $\alpha$ coefficient of the scale in this study was 0.88 .

\section{The Systemic Lupus Erythematosus Disease Activity Index 2000}

The SLEDAI-2K was used to measure the lupus disease activity within the past 30 days. It includes 24 clinical and laboratory variables that are weighted by the organ system. The total score of SLEDAI-2K ranges from 0 to 150 , with higher score indicating higher disease activity. ${ }^{29}$

\section{Statistical analysis}

Descriptive statistics were used to summarize the characteristics of participants. Factors associated with medication nonadherence were explored using logistic regression analysis and are shown as odds ratios (ORs) with 95\% CIs. All statistical analyses were performed using IBM SPSS version 21 , and a $P$-value $<0.05$ was considered statistically significant.

\section{Ethics approval and informed consent}

This study was approved by the West China Hospital Medical Ethics Committee (ID 20160041). The purpose, methods and procedure of the study were explained to the participants, and all of the participants had provided a written informed consent.

\section{Results}

\section{Characteristics of participants}

In total, 142 incident cases of SLE were recruited and included. However, 2 cases were omitted because of incomplete questionnaires, leaving 140 participants in the final analysis. The characteristics of the 140 participants are shown in Table 1. The mean age of participants was 36.9 years, but the majority of them were unemployed $(82.1 \%)$. This may be attributed to the high level of disease activity of participants in our study. The mean SLEDAI-2K score was 10.1. Hair loss, rash, arthritis, low complement and proteinuria were the most frequent manifestations in the SLEDAI-2K. Additionally, a great majority of patients $(82.9 \%)$ had comorbidity, and nephritis and hypertension were the most common. In this study, $65.7 \%$ of patients did not fully understand the instructions on medication provided by their primary physician or nurse and $64.3 \%$ of patients experienced side effects. The mean SF-36 PCS and SF-36 MCS scores was 49.6 and 47.3, respectively,

Table I Characteristics of participants

\begin{tabular}{|c|c|c|c|}
\hline Variables & $\begin{array}{l}\text { Mean } \\
(\mathrm{SD})\end{array}$ & $\begin{array}{l}\text { Minimum, } \\
\text { maximum }\end{array}$ & $\begin{array}{l}\text { Frequency } \\
\text { (\%) }\end{array}$ \\
\hline Age, years & $36.9(13.9)$ & 18,72 & \\
\hline Gender, female & & & $125(89.3)$ \\
\hline Residence, rural & & & $55(39.3)$ \\
\hline Education level, $\leq 9$ years & & & $76(45.0)$ \\
\hline Single & & & $40(28.6)$ \\
\hline Childlessness & & & $41(29.3)$ \\
\hline Unemployed & & & $115(82.1)$ \\
\hline Medical insurance, yes & & & $92(65.7)$ \\
\hline Diagnosis duration, months & $61.6(75.7)$ & I, 363 & \\
\hline SLEDAI-2K & $10.1(4.4)$ & 2,24 & \\
\hline Comorbidity, yes & & & 116 (82.9) \\
\hline \multicolumn{4}{|l|}{ Type of SLE medicine } \\
\hline GC & & & $25(17.9)$ \\
\hline $\mathrm{GC}+\mathrm{HCQ}$ & & & $69(49.3)$ \\
\hline GC+ISD & & & $24(17.1)$ \\
\hline $\mathrm{GC}+\mathrm{HCQ}+\mathrm{ISD}$ & & & $22(15.7)$ \\
\hline $\begin{array}{l}\text { Daily medication more than } \\
\text { once, yes }\end{array}$ & & & $84(60.0)$ \\
\hline $\begin{array}{l}\text { Fully understanding medication } \\
\text { instructions, no }\end{array}$ & & & $92(65.7)$ \\
\hline Side effects experienced, yes & & & $90(64.3)$ \\
\hline Satisfaction with treatment, yes & & & $65(46.4)$ \\
\hline SF-36 PCS score & $49.6(12.1)$ & $24.0,79.8$ & \\
\hline SF-36 MCS score & $47.3(13.7)$ & $19.8,74.7$ & \\
\hline
\end{tabular}

Abbreviations: GC, glucocorticoids; HCQ, hydroxychloroquine; ISD, immunosuppressive drug; SF-36, Short Form 36-item Health Survey; SF-36 MCS, mental component summary of SF-36; SF-36 PCS, physical component summary of SF-36; SLE, systemic lupus erythematosus; SLEDAI-2K, Systemic Lupus Erythematosus Disease Activity Index 2000. 
Table 2 Factors associated with medication nonadherence in patients with SLE

\begin{tabular}{|c|c|c|}
\hline Variables & $\begin{array}{l}\text { Univariate analysis } \\
\text { OR ( } 95 \% \mathrm{Cl} \text {; } \text {-value) }\end{array}$ & $\begin{array}{l}\text { Multivariate analysis } \\
\text { OR ( } 95 \% \mathrm{Cl} \text {; } P \text {-value) }\end{array}$ \\
\hline Age, years & $1.02(0.99-1.05 ; P=0.234)$ & $1.02(0.97-1.07 ; P=0.399)$ \\
\hline Female & I. $10(0.33-3.71 ; P=0.875)$ & $0.64(0.07-5.70 ; P=0.693)$ \\
\hline Rural & $2.74(1.14-6.58 ; P=0.025)$ & $2.90(1.09-7.75 ; P=0.034)$ \\
\hline Education level, $\leq 9$ years & $3.06(1.31-7.15 ; P=0.010)$ & 3.1 I (1.20-8.09; $P=0.020)$ \\
\hline Single & $2.32(0.88-6.10 ; P=0.090)$ & $1.02(0.19-5.49 ; P=0.982)$ \\
\hline Childlessness & $3.13(1.12-8.76 ; P=0.030)$ & $3.21(1.03-10.05 ; P=0.045)$ \\
\hline Unemployed & $0.52(0.16-1.62 ; P=0.258)$ & $0.24(0.05-1.31 ; P=0.100)$ \\
\hline Medical insurance, yes & $0.39(0.16-0.98 ; P=0.044)$ & $0.52(0.13-2.04 ; P=0.348)$ \\
\hline Diagnosis duration, months & $1.01(1.00-1.02 ; P=0.034)$ & $1.01(0.99-1.02 ; P=0.233)$ \\
\hline SLEDAI-2K & $0.93(0.86-1.01 ; P=0.101)$ & $1.03(0.88-1.20 ; P=0.719)$ \\
\hline Comorbidity, yes & $2.08(0.82-5.29 ; P=0.125)$ & $2.24(0.49-10.24 ; P=0.299)$ \\
\hline \multicolumn{3}{|l|}{ Type of SLE medicine } \\
\hline \multicolumn{3}{|l|}{ GC (ref.) } \\
\hline $\mathrm{GC}+\mathrm{HCQ}$ & $0.97(0.33-2.81 ; P=0.949)$ & $0.41(0.07-2.32 ; P=0.310)$ \\
\hline GC+ISD & $0.77(0.22-2.74 ; P=0.683)$ & $0.20(0.03-1.66 ; P=0.137)$ \\
\hline $\mathrm{GC}+\mathrm{HCQ}+\mathrm{ISD}$ & $1.07(0.28-4.16 ; P=0.918)$ & $0.40(0.04-3.60 ; P=0.4 I 2)$ \\
\hline Daily medication more than once, yes & $2.18(1.00-4.74 ; P=0.049)$ & $2.5 \mathrm{I}(0.67-9.39 ; P=0.17 \mathrm{I})$ \\
\hline Full understanding medication instructions, no & $4.33(1.94-9.70 ; P<0.00 I)$ & $3.95(1.56-9.98 ; P=0.004)$ \\
\hline Side effects experienced, yes & $2.84(1.29-6.22 ; P=0.009)$ & $2.42(I . I I-5.28 ; P=0.027)$ \\
\hline Satisfaction with treatment, yes & $0.29(0.13-0.66 ; P=0.003)$ & $0.29(0.09-0.93 ; P=0.037)$ \\
\hline SF-36 PCS score & $1.04(I .01-1.08 ; P=0.020)$ & $1.12(I .03-1.22 ; P=0.007)$ \\
\hline SF-36 MCS score & $1.00(0.98-1.03 ; P=0.813)$ & $0.95(0.89-1.01 ; P=0.110)$ \\
\hline
\end{tabular}

Note: The bold value indicates statistical significance at the 0.05 level.

Abbreviations: GC, glucocorticoids; HCQ, hydroxychloroquine; ISD, immunosuppressive drug; OR, odds ratio; SF-36, Short Form 36-item Health Survey; SF-36 MCS, mental component summary of SF-36; SF-36 PCS, physical component summary of SF-36; SLE, systemic lupus erythematosus; SLEDAI-2K, Systemic Lupus Erythematosus Disease Activity Index 2000.

indicating poor physical health and mental health of this cohort.

\section{The proportion of patients not adhering to medication and predictors thereof}

In keeping with an MMAS- $8 \leq 6,105(75 \%)$ cases in the sample of patients did not adhere to SLE treatment. In the multiple logistic regression analysis, as shown in Table 2, the risk for medication nonadherence to SLE treatment was significantly higher for those with a low level of education, rural residency, childlessness, limited comprehension of medication instructions, side effects experienced, dissatisfaction with treatment and better physical health.

\section{Discussion}

In our study, we investigated the prevalence of medication nonadherence among Chinese SLE patients using a selfreport questionnaire MMAS-8 and explored its predictors. According to the cutoff criteria of MMAS- 8 for medication nonadherence, we found that $75 \%$ of the participants were categorized as nonadherent.

A recent systematic review of medication adherence among SLE patients has shown that over half of the patients are nonadherent to medication, ${ }^{12}$ results that are similar to our finding. It suggests that, as elsewhere, nonadherence is common in patients with SLE in Sichuan, China. Considering the negative impacts of medication nonadherence on patients' outcome, health care utilization and $\operatorname{cost}^{8-10}$ studies aimed at developing strategies to promote adherence among these patients are needed.

In terms of predictors of medication nonadherence, our study revealed that the risk of medication nonadherence was higher for those who live in rural region, which agrees with the finding of Abdul-Sattar and Abou El Magd. ${ }^{17}$ One of the possible reasons may be the fact that rural communities usually lack rheumatologic services, and poor availability of health care increases the risk of nonadherence. ${ }^{30}$ It suggests to policymakers that appropriate adjustment of the service resources for patients with rheumatic disease in rural communities may contribute to improve the adherence of SLE patients. Another possible reason for the higher risk of nonadherence in rural patients is their low level of education. Nonadherence in our study was associated with lower level of education, which is consistent with an adherence study conducted in USA by Garcia-Gonzalez et al. ${ }^{31}$ These results may be attributed to the fact that patients with lower level of 
education often have less knowledge of medication and poor comprehension of consequences of nonadherence. ${ }^{32}$ Thus, improving the medication knowledge of patients, especially of patients with low education, may help to improve the adherence in patients with SLE. Side effect experienced is another factor associated with nonadherence in this study, which concurs with previous studies. ${ }^{11,12}$ Oliveira-Santos et al ${ }^{15}$ have shown that $13.8 \%$ of SLE patients stopped taking their medicine because it made them feel worse. These results reflect that the patient does not know how to properly cope with the discomfort caused by taking medicines, and to alleviate the discomfort, medication is discontinued. Therefore, improving the coping skills for self-management of treatment, side effects perhaps can reduce medication nonadherence in SLE patients. This view has been confirmed in other chronic conditions. ${ }^{33}$

Additionally, the observed association between nonadherence and comprehension of medication instructions, treatment satisfaction and perceived physical health in this study agrees with some studies conducted in other chronic diseases. ${ }^{20-23}$ First, limited comprehension of medication instructions significantly increased the risk of nonadherence in patients with SLE. In our study, $65.7 \%$ of the patients reported limited comprehension of medication instructions, which may reflect poor doctor-patient communication. Previous qualitative data have shown that poor communication is an important barrier to adherence in SLE patients. ${ }^{34}$ Therefore, improved communication between the health care provider and the patient is needed, and it may be beneficial to improve the adherence of this cohort. Second, we found that nonadherence was more common among participants who were not satisfied with treatment. Previous studies performed in other chronic diseases have linked treatment satisfaction to patients' attitudes or beliefs toward taking medications, which is recognized to be a precursor to medication adherence. ${ }^{35}$ So, it can be speculated that interventions aimed at improving patients' attitudes or beliefs toward taking medications may improve patients' treatment satisfaction and also can improve their adherence. Third, those who perceived better physical health in our study were more likely to be nonadherent, which is in accordance with a previous study that reported $7.72 \%$ of the patients stop taking medicine when they feel better. ${ }^{15}$

Although two studies have shown that being single is the predictor of nonadherence in SLE patients, ${ }^{16,36}$ our study did not find the correlation between marital status and adherence. However, we found that nonadherence is more common in those who are childless. This may be explained by the impact of fertility concerns on adherence in patients with SLE. For many SLE patients, the illness coincides with their childbearing years, and they may fear of a negative effect of medication on fertility/fetus. According to a survey by Xu et al, ${ }^{37} 79 \%$ of SLE patients believe that they should stop taking glucocorticoids when they are planning to have children. The fact is, however, that the adherence to glucocorticoids before, during and after pregnancy is important for the safety of the mother and the infant ${ }^{38}$ Health care workers should enhance fertility guidance in this group to correct their misperception in this area, which may also improve their medication adherence.

There are several possible limitations to our study. First, due to limited time and financial constraints, the study was conducted at a single center, which may have resulted in overestimation or underestimation of the prevalence of medication nonadherence of SLE patients in Sichuan, China. This is mitigated by the fact that the chosen center was a large tertiary referral hospital serving patients from a wide cross section of Sichuan. Second, we selected a self-report questionnaire as a tool for measuring adherence. Though the validity of the self-report adherence tool has been questioned in earlier studies, ${ }^{39}$ in more recent reports, it has been found to compare favorably with the electronic monitoring devices. ${ }^{40,41}$ Third, our study is a cross-sectional study which allows only for correlation, not causation. Fourth, more details on patients were not collected, which may have had an impact on adherence. These limitations should be addressed in future related studies.

\section{Conclusion}

Our study demonstrates that there is a great prevalence of medication nonadherence among SLE patients in Sichuan, China. Given the negative consequences of nonadherence, patients should be assessed for early identification and intervention. What is more, our study reveals that patients would be at increased risk for nonadherence if they have low education, live in a rural region, are childless, have limited comprehension of medication instructions, have experienced side effects, are not satisfied with the treatment, and have better physical health. These findings suggest that patients' adherence may be improved by interventions for these factors, such as appropriate adjustment of the service resources for patients with rheumatic disease in rural communities and improved communication between the health care providers and the patients, including the need for health care providers to identify and discuss any questions and concerns which the patient may have regarding their disease and its medications. 


\section{Acknowledgments}

The authors thank all patients for sincerely completing our investigation and staff at the Rheumatic Clinic of West China Hospital Sichuan University for supporting this study. Use of the CMMAS is protected by US copyright laws. Permission for use is required. A license agreement is available from Donald E. Morisky, ScD, ScM, MSPH, 14725 NE 20th St Bellevue, WA 98007, USA; dmorisky@gmail.com. They also thank Dr Morisky for giving them permission to use the eight-item Morisky Medication Adherence Scale.

\section{Disclosure}

The authors report no conflicts of interest in this work.

\section{References}

1. Jakes RW, Bae SC, Louthrenoo W, Mok CC, Navarra SV, Kwon N. Systematic review of the epidemiology of systemic lupus erythematosus in the Asia-Pacific region: prevalence, incidence, clinical features, and mortality. Arthritis Care Res. 2012;64(2):159-168.

2. Flower C, Hennis AJM, Hambleton IR, Nicholson GD, Liang MH. Systemic lupus erythematosus in an Afro-Caribbean population: incidence, clinical manifestations and survival in the Barbados national lupus registry. Arthritis Care Res. 2012;64(8):1151-1158.

3. Bernatsky S, Boivin JF, Joseph L, et al. Mortality in systemic lupus erythematosus. Arthritis Rheum. 2006;54(8):2550-2557.

4. Carter EE, Barr SG, Clarke AE. The global burden of SLE: prevalence, health disparities and socioeconomic impact. Nat Rev Rheumatol. 2016;12(10):605-620.

5. Kiani AN, Petri M. Quality-of-life measurements versus disease activity in systemic lupus erythematosus. Curr Rheumatol Rep. 2010; 12(4):250-258.

6. Gladman DD, Urowitz MB, Esdaile JM, et al. Guidelines for referral and management of systemic lupus erythematosus in adults. Arthritis Rheum. 1999;42(9):1785-1796.

7. Lam NC, Ghetu MV, Bieniek ML. Systemic lupus erythematosus: primary care approach to diagnosis and management. Am Fam Physician. 2016;94(4):284-294.

8. Feldman CH, Yazdany J, Guan H, Solomon DH, Costenbader KH. Medication nonadherence is associated with increased subsequent acute care utilization among medicaid beneficiaries with systemic lupus erythematosus. Arthritis Care Res. 2015;67(12):1712-1721.

9. Chambers SA, Rahman A, Isenberg DA. Treatment adherence and clinical outcome in systemic lupus erythematosus. Rheumatology. 2007; 46(6):895-898.

10. Bruce IN, Gladman DD, Urowitz MB. Factors associated with refractory renal disease in patients with systemic lupus erythematosus: the role of patient nonadherence. Arthritis Care Res. 2000;13(6):406-408.

11. Costedoat-Chalumeau N, Pouchot J, Guettrot-Imbert G, et al. Adherence to treatment in systemic lupus erythematosus patients. Best Pract Res Clin Rheumatol. 2013;27(3):329-340.

12. Mehat P, Atiquzzaman M, Esdaile JM, Aviña-Zubieta A, de vera MA. Medication nonadherence in systemic lupus erythematosus: a systematic review. Arthritis Care Res. 2017;69(11):1706-1713.

13. Wang ZH, Chen HY, Mc Y, Chen SX. Survey of treatment compliance and influencing factors in systemic lupus erythematosus patients. Chongqing Med. 2010;39(2):220-221.

14. Garcia Popa-Lisseanu MG, Greisinger A, Richardson M, et al. Determinants of treatment adherence in ethnically diverse, economically disadvantaged patients with rheumatic disease. J Rheumatol. 2005;32(5): 913-919.
15. Oliveira-Santos M, Verani JF, Klumb EM, Albuquerque EM. Evaluation of adherence to drug treatment in patients with systemic lupus erythematosus in Brazil. Lupus. 2011;20(3):320-329.

16. Koneru S, Kocharla L, Higgins GC, et al. Adherence to medications in systemic lupus erythematosus. J Clin Rheumatol. 2008;14(4): 195-201.

17. Abdul-Sattar AB, Abou El Magd SA. Determinants of medication non-adherence in Egyptian patients with systemic lupus erythematosus: Sharkia Governorate. Rheumatol Int. 2015;35(6):1045-1051.

18. Daleboudt GM, Broadbent E, Mcqueen F, Kaptein AA. Intentional and unintentional treatment nonadherence in patients with systemic lupus erythematosus. Arthritis Care Res. 2011;63(3):342-350.

19. Alsowaida N, Alrasheed M, Mayet A, Alsuwaida A, Omair MA. Medication adherence, depression and disease activity among patients with systemic lupus erythematosus. Lupus. 2018;27(2):961203317725585.

20. Alexender S, Golin C, Kalinowski C. Provider-patient communication and treatment adherence. In: Bosworth H, Oddone E, Weinberger M, editors. Patient Treatment Adherence: Concepts, Interventions, and Measurement. London: Lawrence Erlbaum; 2005:329-372.

21. Dimatteo MR. Patient adherence to pharmacotherapy: the importance of effective communication. Formulary. 1995;30(10):596-598.

22. Zyoud SH, Al-Jabi SW, Sweileh WM, Morisky DE. Relationship of treatment satisfaction to medication adherence: findings from a crosssectional survey among hypertensive patients in Palestine. Health Qual Life Outcomes. 2013;11(1):191.

23. Fogel J, Fauerbach JA, Ziegelstein RC, Bush DE. Quality of life in physical health domains predicts adherence among myocardial infarction patients even after adjusting for depressive symptoms. J Psychosom Res. 2004;56(1):75-82.

24. Hochberg MC. Updating the American College of Rheumatology revised criteria for the classification of systemic lupus erythematosus. Arthritis Rheum. 1997;40(9):1725.

25. Morisky DE, Ang A, Krousel-Wood M, Ward H. Predictive validity of a medication adherence measure for hypertension control. J Clin Hypertens. 2008;10(5):348-354.

26. Lee GK, Wang HH, Liu KQ, Cheung Y, Morisky DE, Wong MC. Determinants of medication adherence to antihypertensive medications among a Chinese population using Morisky Medication Adherence Scale. PLoS One. 2013;8(4):e62775.

27. Ho CP, Tjf L. The reliability and validity of the chinese version of the eight-item Morisky Medication Adherence Scale. Value Health. 2014; 17(7):A730

28. Liu J, Shu Q, Wang JZ. Evaluation of quality of life of patients with systemic erythematosus lupus using SF-36. Chin J Public Health. 2004;20(11):1383-1384.

29. Gladman DD, Ibañez D, Urowitz MB. Systemic Lupus Erythematosus Disease Activity Index 2000. J Rheumatol. 2002;29(2):288-291.

30. Chambers S, Raine R, Rahman A, Hagley K, de Ceulaer K, Isenberg D. Factors influencing adherence to medications in a group of patients with systemic lupus erythematosus in Jamaica. Lupus. 2008;17(8): 761-769.

31. Garcia-Gonzalez A, Richardson M, Garcia Popa-Lisseanu M, et al. Treatment adherence in patients with rheumatoid arthritis and systemic lupus erythematosus. Clin Rheumatol. 2008;27(7):883-889.

32. An L, Wang X-Y, Wang J. Cognition altitude and behavior of patients with systemic lupus erythematosus on use of hormone and research of influence factors and countermeasures. Medical Journal of National Defending Forces in Southwest China. 2014;24:2037-2039. China.

33. Johnson MO, Dilworth SE, Taylor JM, Neilands TB. Improving coping skills for self-management of treatment side effects can reduce antiretroviral medication nonadherence among people living with HIV. Ann Behav Med. 2011;41(1):83-91.

34. Chambers SA, Raine R, Rahman A, Isenberg D. Why do patients with systemic lupus erythematosus take or fail to take their prescribed medications? A qualitative study in a UK cohort. Rheumatology. 2009; 48(3):266-271 
35. Barbosa CD, Balp MM, Kulich K, Germain N, Rofail D. A literature review to explore the link between treatment satisfaction and adherence, compliance, and persistence. Patient Prefer Adherence. 2012;6: 39-48.

36. Marengo MF, Waimann CA, de Achaval S, et al. Measuring therapeutic adherence in systemic lupus erythematosus with electronic monitoring. Lupus. 2012;21(11):1158-1165.

37. Xu P, Mian J, Cao B-Y, Liang J. A survey on the cognition and guidance demand of fertility in patients with systemic lupus erythematosus. J Adv Nurs. 2016;23:39-41.

38. The Chinese SLE Treatment and Research group (CSTAR). Pregnancy management recommendation of patients with systemic lupus erythematosus in China. BMJ. 2015;95:1056-1060.

39. Spector SL, Kinsman R, Mawhinney H, et al. Compliance of patients with asthma with an experimental aerosolized medication: implications for controlled clinical trials. J Allergy Clin Immunol. 1986;77(1 Pt 1): $65-70$.
40. Zeller A, Schroeder K, Peters TJ. An adherence self-report questionnaire facilitated the differentiation between nonadherence and nonresponse to antihypertensive treatment. J Clin Epidemiol. 2008;61(3): $282-288$.

41. Schroeder K, Fahey T, Hay AD, Montgomery A, Peters TJ. Adherence to antihypertensive medication assessed by self-report was associated with electronic monitoring compliance. J Clin Epidemiol. 2006; 59(6):650-651.

42. Morisky DE, DiMatteo MR. Improving the measurement of selfreported medication nonadherence: Final response. J Clin Epidem. 2011;64:258-263.

43. Berlowitz DR, Foy CG, Kazis LE, et al. for the SPRINT Study Research Group. Impact of Intensive Blood Pressure Therapy on Patient-Reported Outcomes: Outcomes Results from the SPRINT Study. NEngl J Med. 2017;377:733-744.

\section{Publish your work in this journal}

Patient Preference and Adherence is an international, peer-reviewed, open access journal that focuses on the growing importance of patient preference and adherence throughout the therapeutic continuum. Patient satisfaction, acceptability, quality of life, compliance, persistence and their role in developing new therapeutic modalities and compounds to optimize clinical outcomes for existing disease states are major areas of interest for the journal. This journal has been accepted for indexing on PubMed Central. The manuscript management system is completely online and includes a very quick and fair peer-review system, which is all easy to use. Visit http://www. dovepress.com/testimonials.php to read real quotes from published authors.

Submit your manuscript here: http://www.dovepress.com/patient-preference-and-adherence-journal 